\title{
Fragen zum Thema „Diagnostik der Herzinsuffizienz“
}

\author{
1. Welcher Befund ist nicht typisch für eine \\ Herzinsuffizienz? \\ A Halsvenenstauung \\ B Müdigkeit \\ C Dritter Herzton \\ D Systolisches Mitralinsuffizienzgeräusch \\ E Kleine, indurierte Leber
}

\section{-2. In welchem Punkt erlaubt die Ruhe-Echo- kardiografie keine zuverlässige diagnostische Aussage?}

A Abschätzung der Ejektionsfraktion.

B Nachweis eines Klappenvitiums.

C Differenzierung zwischen Kardiomyopathie und koronarer Herzkrankheit bei schwer eingeschränktem linkem Ventrikel.

D Beurteilung der Größe des rechten Ventrikels.

E Messung des Querdurchmessers des linken Ventrikels.

\section{- 3. Welche Aussage zu den natriuretischen Peptiden trifft nicht zu?}

A BNP und NT-proBNP steigen bei Herzinsuffizienz an.

B Die diagnostische Stärke der natriuretischen Peptide liegt v. a. im Ausschluss einer Herzinsuffizienz bei niedrigen Serumspiegeln.

C Wenn BNP erhöht ist, liegt in über 90\% eine Herzinsuffizienz vor.

D Die Ausschüttung von BNP erfolgt auf Dehnungsreiz im linken Vorhof und Ventrikel hin.

E Die Spiegel der natriuretischen Peptide korrelieren mit dem Schweregrad der Herzinsuffizienz.

\author{
-4. Die folgenden EKG-Veränderungen sind bei \\ Herzinsuffizienz häufig, außer: \\ A Delta-Welle. \\ B Linksschenkelblock. \\ C Pathologische Q-Zacken als Zeichen abge- \\ laufener Infarkte. \\ D T-Abflachung. \\ E Vorhofflimmern.
}

\section{-5. Das Röntgenbild des Thorax bei Herzinsuffizienz}

A kann Kerley-B-Linien zeigen.

B zeigt ein kleines, steilgestelltes Herz.

C sollte auch bei stabiler Symptomatik in halbjährlichen Abständen erfolgen.

D sollte in der Regel durch eine Computertomografie ersetzt werden.

E zeigt häufig Rippenusuren.

\section{-6. Welche Aussage trifft nicht zu?}

A Die schwere Herzinsuffizienz hat bei adäquater Behandlung meist eine gute Prognose.

B Herzinfarkt und dilatative Kardiomyopathie sind häufige Ursachen einer eingeschränkten kardialen Pumpleistung.

C Wenn bei herzinsuffizienten Patienten vitales, kontraktionsgestörtes Myokard nachgewiesen wird, kann durch Revaskularisation eventuell die Ventrikelfunktion gebessert werden.

D Der „diastolischen Herzinsuffizienz" liegt oft ein arterieller Hypertonus zugrunde.

E Brain Natriuretic Peptide (BNP) wird in Vorhof und Ventrikel gebildet.

-7. Welcher Lungenauskultationsbefund ist typisch für eine Linksherzinsuffizienz?

A Giemen
B Pleurareiben

C Brummen und Pfeifen

D Feinblasige Rasselgeräusche

E Verschärftes Atemgeräusch

- 8. Welche der folgenden einfachen Maßnahmen erscheinen Ihnen bei akuter Linksherzinsuffizienz sinnvoll?

A Patienten flach hinlegen

B Patienten aufsetzen, Beine aus dem Bett hängen lassen

C Kopftieflage

D Beine hochlagern

E Patienten durch ein Rohr atmen lassen

-9. Was versteht man unter „Herzfehlerzellen“?

A Hypertrophierte Myokardzellen bei Herzvitien

B Lymphoplasmazelluäre Infiltrate im Interstitium bei Myokarditis

C Hämosiderinhaltige Alveolarmakrophagen im Sputum

D Verfettete Herzmuskelzellen

E Nekrotische Herzmuskelareale beim Myokardinfarkt

-10. Welche der folgenden Aussagen trifft nicht zu? Patienten mit chronischer Herzinsuffizienz sollten

A wenn eine stabile Rekompensation erreicht ist ein leichtes regelmäßiges Konditionstraining durchführen.

B sich salzarm ernähren.

C sich regelmäßig wiegen.

D nicht mehr als 1,5 Liter pro Tag trinken.

E sich salzreich ernähren.

\section{ANTWORTFORMULAR}

Ich versichere, alle Fragen ohne fremde Hilfe beantwortet zu haben.

Mit dem Einreichen dieses Fragebogens erklärt sich der Einreichende damit einverstanden, dass die angegebenen Daten zum Zweck der Teilnahmebestätigung gespeichert und bei erfolgreicher Teilnahme auch an den Einheitlichen Informationsverteiler (EIV) der Ärztekammern weitergegeben werden.
„Diagnostik der Herzinsuffizienz“

MMW-Fortschr. Med. Nr. 49-50 / 2006 (148. Jg.)

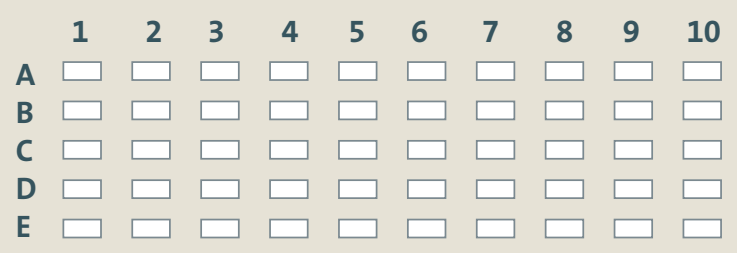

Bitte kreuzen Sie pro Frage je eine Antwort deutlich an.
Und so kommen Sie zu Ihren Punkten:

Teilnahme im Internet: unter www.cme-punkt.de. Dort führen wir für Sie ein elektronisches Punktekonto.

Teilnahme per Brief: Fragebogen ausfüllen und mit einem frankierten Rückumschlag an: Urban \& Vogel Medien und Medizin Verlagsgesellschaft, Redaktion MMW-Fortschritte der Medizin, Abt. Fortbildungszertifikat, Neumarkter Str. 43, 81673 München. 